\title{
Mechanical behaviour of Composites based on Diss and Aflfa fibres in different matrices
}

\author{
Zohra Belkhir ${ }^{1 *}$, Mouloud Merzoud ${ }^{2}$ and Amar Benazzouk ${ }^{3}$ \\ ${ }^{1}$ Laboratoire des Mines, Département de Génie Civil, Université Larbi Tebessi, Tebessa 12000, Algérie* \\ ${ }^{2}$ Laboratoire de Génie Civil, Université Badji Mokhtar de Annaba, BP 12 Annaba, 23000, Algérie \\ ${ }^{3}$ Laboratoire des Technologies Innovantes, Département de Génie Civil, IUT Université Picardie Jules Verne, Avanue des facultés \\ Amiens 80025 Cedex 1 France
}

\begin{abstract}
The use of natural fibers in cementitious matrices has an incompatibility, which results considerable retardation of setting and very low resistances during the composite tests with natural crushed Diss, despite the fact that the fibers have considerable tensile strengths, because of the sugars and watersoluble components contained in natural plants. To improve the fibers contribution in cementitious composites, we have carried out a treatment by boiling the natural fibers to extract the substances responsible for the bad connection between fibers and the cement paste. This phenomenon of incompatibility disappears with the use of clay matrix or lime, which allows using the fibers without any treatment. We were able to determine the mechanical behavior of composites in flexion and compression by measuring stresses and deformations. Through our vast experimental program on the composites of natural fibers of Alfa and Diss in different matrices (cement and clay) and different sizes ranging from 2 to $8 \mathrm{~cm}$, we have found: 1) The best resistance in bending and compression are generally reached for the composites with fibers having the dimensions between 4 and $6 \mathrm{~cm}$. 2) The best bending strengths are achieved for composites with cementitious matrices, because of the good adhesion of the fibers to the matrix. 3) The best compressive strengths are achieved for clay matrix composites, which are due to the good compressibility of the clay. 4) The composites of Alfa and Diss fibers presented a very ductile behavior as well in flexion as in compression, contrary to the pure binder paste which has a brittle behavior. 5) The composites obtained have a very low density, which makes it possible to classify them as lightweight materials and have a very ductile behavior, which suggests using these materials as filling in the seismic zones.
\end{abstract}

\section{Introduction}

This study concerns the examination of the feasibility of a composite material based on Alfa and Diss fibers. These materials fit perfectly into a sustainable development approach, whether to develop renewable natural resources or, thanks to their biodegradable nature, to limit the production of waste. To understand the problems of chemical incompatibility, observed in cementitious matrix composites, which is not the case for the clay matrix.

Aamar Daya E.H [1] used dust from the stripping of flax fibres as aggregate in a composite with cementing matrix. His works showed that the treatment of flax dust with boiled water improves, considerably the mechanical resistance of the composites.

Fertikh S et al [2] highlighted composites based on boiled and unboiled diss fibers in clay matrices; they found that unboiled diss fibers give better mechanical performance than boiled diss, since the hydrothermal treatment modifies the morphology of the fibers, and thus causing a bond at the much more fragile fiber / matrix interface. The use of vegetable fibers in their natural state in clay matrices does not require any treatment beforehand, whereas in the case of cement matrix the hydrothermal treatment is essential to eliminate the water-soluble constituents responsible for the setting delay and the loss of resistance.

Fertikh et al [3] have shown that the use of clay or the clay-lime combination in composites based on natural fibers such as diss can overcome the inhibition phenomena that occur in the case of 'a cement matrix.

Natural fibers do not interact well with cement paste because of the water-soluble inhibitory substances and particularly sugars, which generally manifest themselves as a delay in setting, and the loss of resistance of the material. This effect disappears completely with the clay matrices. With the same objective, other work has been carried out on diss concrete, highlighting the inhibitory effect that diss fibers exerted on the binder [4].

Sellami et al. [5] evaluated the effect of treatment with boiling water of Diss fibers on the mechanical properties of a mortar incorporating this reinforcement. This treatment consisted in removing the extractables by

\footnotetext{
* Corresponding author: zohra.belkhir@univ-tebessa.dz
} 
distillation in water. They noted a strong improvement in the flexural strength of the composite of treated fibers in comparison with that of natural fibers.

Merzoud's work related to the optimization of a cementitious composite containing Diss with the application of various treatments [6]. It appears clearly that if the boiling water treatment increases the performances of the composite thanks to the elimination of the water-soluble compounds, but the coating with linseed oil of fibres previously boiled is the most powerful far among those which were tested. For similar composite bulk densities, the compressive and tensile strengths diss fibres coated with linseed oil composites (Tr3) are higher than those obtained with boiling diss fibres ( $\operatorname{Tr} 2)$. This is explained by the fact that the thorny structure is still present during the treatment $(\operatorname{Tr} 3)$. Moreover, the fibres are placed horizontally and in parallel, which tends to increase their role of reinforcement. The diss fibres coated with bitumen $(\operatorname{Tr} 4)$ gave lower compressive and traction strengths, because of disappearance of the spines and the random disposition of fibres in the composite.

These results show clearly the interest to use such a material as resistant fillings and even as structural elements for structures situated in seismic zones, because of their lightness, resistance and high ductility.

Building materials, of bio-sourced types, have been the subject of several research studies. In addition to their low densities, they have interesting thermal and acoustic properties. However, their sensitivity to water is an obstacle to their industrial development. To overcome this phenomenon of water absoption, physical treatments of impregnation or surface coating of inclusions have been studied [7].

In the same context, other work on the formulation of concrete and / or mortar, based on agro-resources, has shown that the performance of the latter depends on the nature of the plant fibers and their dimensions [8] [9]. In addition, their incorporation improves the tensile strength, ductility or post-fracture behavior of composites.

In this field, bio-sourced materials (based on plant particles) constitute a potential response to the need for materials compatible with sustainable construction, meeting regulatory requirements,

In this study, the aim is to evaluate the physicomechanical properties of a material, with a cementitious and clay matrix, The Diss fibers/binder ratio was set to 4:1 (by volume) for all formulations, with different dimensions ranging from 2 to $8 \mathrm{~cm}$.

\section{Material and experimental methods}

The Diss used was collected in the region of SoukAhras, and the Alfa of the Tebessa region, cities in eastern Algeria. They are annuals, and have very good tensile strengths. Bending tensile tests of natural fiber composites are carried out using a three-point bending setup, equipped with an automatic data acquisition system, on prismatic test pieces $(4 * 4 * 16 \mathrm{~cm})$, figure (1-a). The compression tests are carried out on half of the specimens tested in flexion, and the strengths were determined according to the ASTM D 695 standard (Figure. 1-b). Both tests were performed using a machine type Zwick/Roell 20KN.Fig. 1.
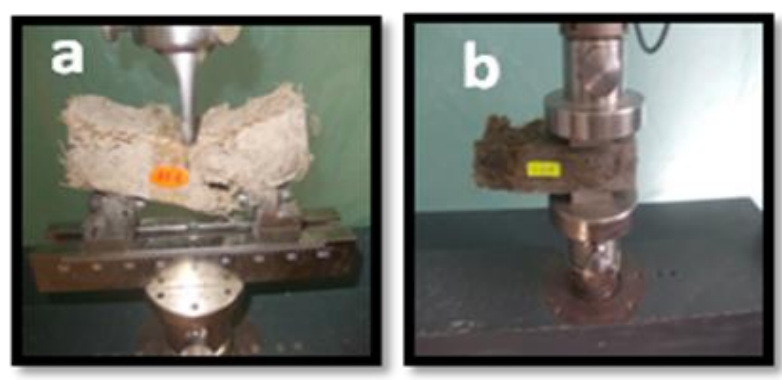

Fig 1 a: Flexion Test setup, 1-b: Compression

\section{Results and discussion}

The results of the three-point bending and compression testing of Diss and Alfa fibers composites in cementitious and clay matrices are shown in Figures 2 to 5.

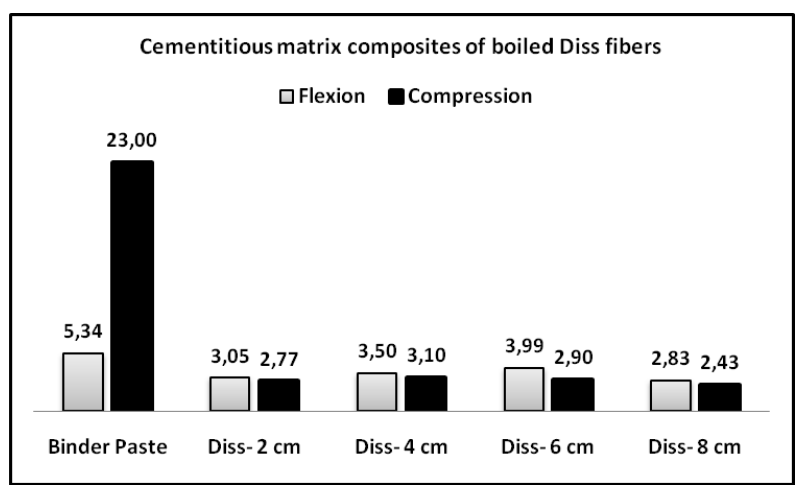

Fig 2 Mechanical Stresses of Diss Composites with cementitous matrix

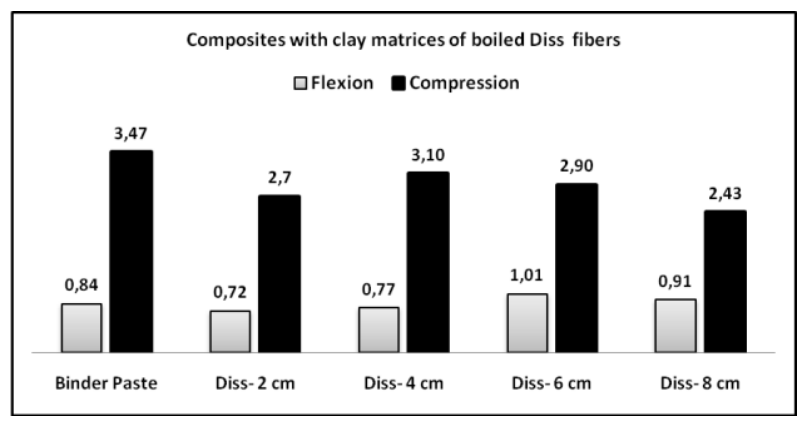

Fig 3 Mechanical Stresses of Clay-based Diss Composites 


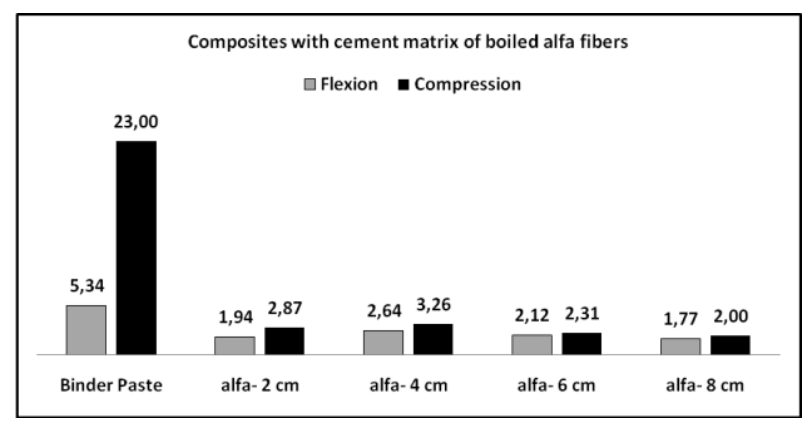

Fig 4 Mechanical Stresses of Alfa Composites with cementitous matrix

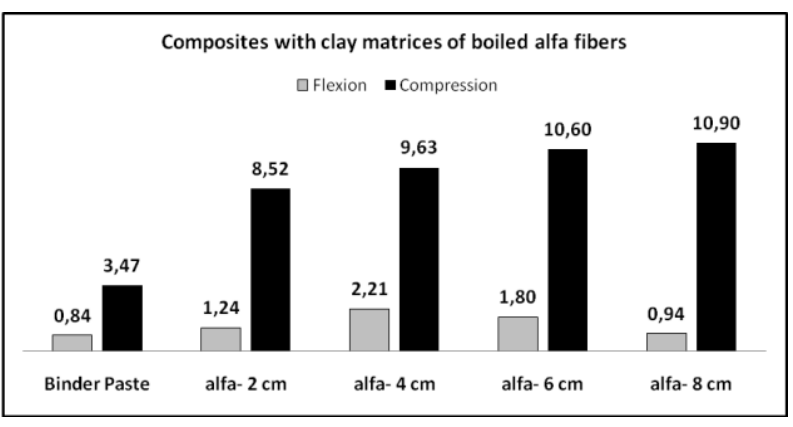

Fig 5 Mechanical Stresses of Alfa Clay Composites

Experimental results show that the best flexural and compressive strengths of composites based on Diss fibers are reached between 4 and $6 \mathrm{~cm}$, as well as the flexion of composites based on Alfa fibers, whereas their compression increases with dimensions of the fibers.
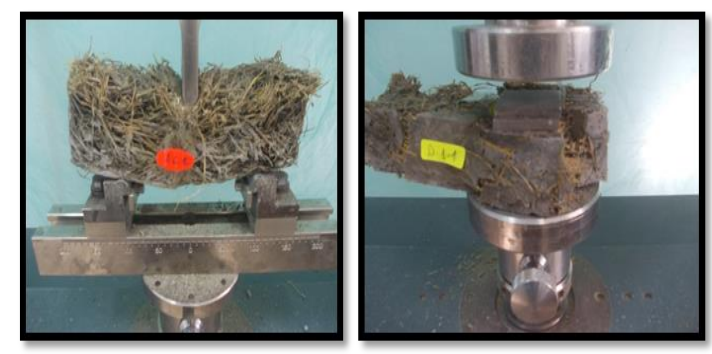

Fig 6 Bending and Compression Testing of Composites Based on Natural Fibers

\section{Conclusions}

The tests carried out on composites based on Diss fibers and Alfa in different matrices (cementitious and clay) and different dimensions which can range from 2 to 8 $\mathrm{cm}$, we found, that the best resistance in bending and compression are generally reached for 4 and $6 \mathrm{~cm}$ fiber composites, with the exception of Alfa fibers subjected to compression, where the largest values vary between 4 and $8 \mathrm{~cm}$. It is also noted that the strengths of Diss and Alfa composites with argillaceous matrix give very high compressive values, comparable to pure clay paste for Diss fibers, but more important for composites based on Alfa fibers, because of the good compressibility of the clay paste. The composites obtained have a very low density, which makes it possible to classify the composites based on the natural fibers as light materials, with a very ductile behavior, which allows to consider using these materials as filling in the seismic zones.

\section{References}

1. E. Amar-Daya, T. Langlet, A. Benazzouk., Cement and Concrete Composites 30, 957 (2008).

2. S. Fertikh, M. Merzoud, M.F. Habita, A. Benazzouk,. XXIXe Rencontres Universitaires de Génie Civil. Université de Tlemcen-Algérie 188196 (2011).

3. S. Fertikh, M. Merzoud, M. Bounadja, A. Ghania, A. Benazzouk, Annales du Batiment et des Travaux Publics, Decembre 6 (2012).

4. M. Merzoud, A. Sellami, A. Gouasmia, A. Benazzouk, Conférence Internationale Francophone NoMaD (Nouveau Matériaux et Durabilité), LGCGE-Ecole des Mines de Douai, Lille Nord de France (2015).

5. A. Sellami, M. Merzoud, S. Amziane, Construction and Building Materials, 47, 1117 (2013).

6. M. Merzoud, R.M. Dheilly, A. Goulleux, M. Queneudec, M.F Habita, Proceeding of the 7th International Congress 8-10 July 2008, Dundee Scoltand, U.K, Edition IHS BRE presse, ISBN-13: 978-1-84806-037-1, pp 651-660 (2008).

7. D. Romildo, T. Filho, K. Ghavami, G.L. England, K. Scrivener,. Cement and Concrete Composites, 25(2), 185 (2003).

8. R.R. Almeida, C.H.S. Del Menezzi, D.E. Teixeira, Bioressource Technolgy, 85, 159 (2002).

9. M. Abdelmouleh, S. Boufi, M.N. Belgacem, A. Dufresne, Composites Science and Technology, 67,1627 (2007). 